\title{
MULTIPLE BENIGN TUMOR-LIKE GROWTHS OF SCHWENINGER AND BUZZI*
}

\author{
S. E. SWEITZER, M.D. \\ MINNEAPOLIS
}

Schweninger and Buzzi, ${ }^{1}$ in 1891, under the title "Multiple Benign Tumor-Like Growths" described a unique anomaly of the skin.

Crocker ${ }^{2}$ gave a very good description of this condition, which we cannot improve on. He wrote: "Clinically, the lesions are soft, round or oval projections, from a lentil to a bean in size, more or less white, with a slight blush or slate color in some of them. Most of them are bladder-like, and can be pressed into the skin by the finger, projecting immediately again like a hernia. The larger ones are flattened and slightly puckered, and harder than the smaller, from which they develop. They undergo spontaneous resolution, and leave only flaccid, loose, foveated scars. They appear very gradually and without sensory symptoms on the trunk, shoulders and thighs and ultimately become numerous, as none disappear entirely, and others keep forming."

Further on, Crocker says: "I have seen very similar lesions associated with fibromata of the ordinary form, when some of them have been absorbed. It is probable that they are the last phase of more than one pathological process."

T. Colcott Fox ${ }^{3}$ reported a similar case seen by him. and refers in his article to a case seen by Malcolm Morris and one seen by Van Hoorn. Morris saw the original case of Schweninger and Buzzi and claimed that these three cases were of a similar nature, although no biopsies were made.

Stelwagon, ${ }^{4}$ in his book, reported one case which, from his description, seems to belong in this category.

Pusey, ${ }^{5}$ in 1917, read a paper on this condition and made a complete report of a case, with microscopic findings. He found a diminution in the elastic fibers.

* Read at the Forty-Fifth Annual Meeting of the American Dermatological Association, Washington. D. C., May 2-4, 1922.

1. Schweninger and Buzzi: International Atlas of Rare Skin Diseases, 1891, Part 5, Plate 15.

2. Crocker: Diseases of the Skin, E.d. 3, Philadelphia, P. Blakiston's Son \& Co., 1903, p. 702.

3. T. Colcott Fox: Multiple Benign Tumor-Like New Growths of the Skin, Brit. J. Dermat. 4:117-119, 1892.

4. Stelwagon: Diseases of the Skin, Ed. 8, Philadelphia, W. B. Saunders Company, 1916, p. 696.

5. Pusey, W. A.: J. Cutan. Dis. 35:582 (Sept.) 1917. 


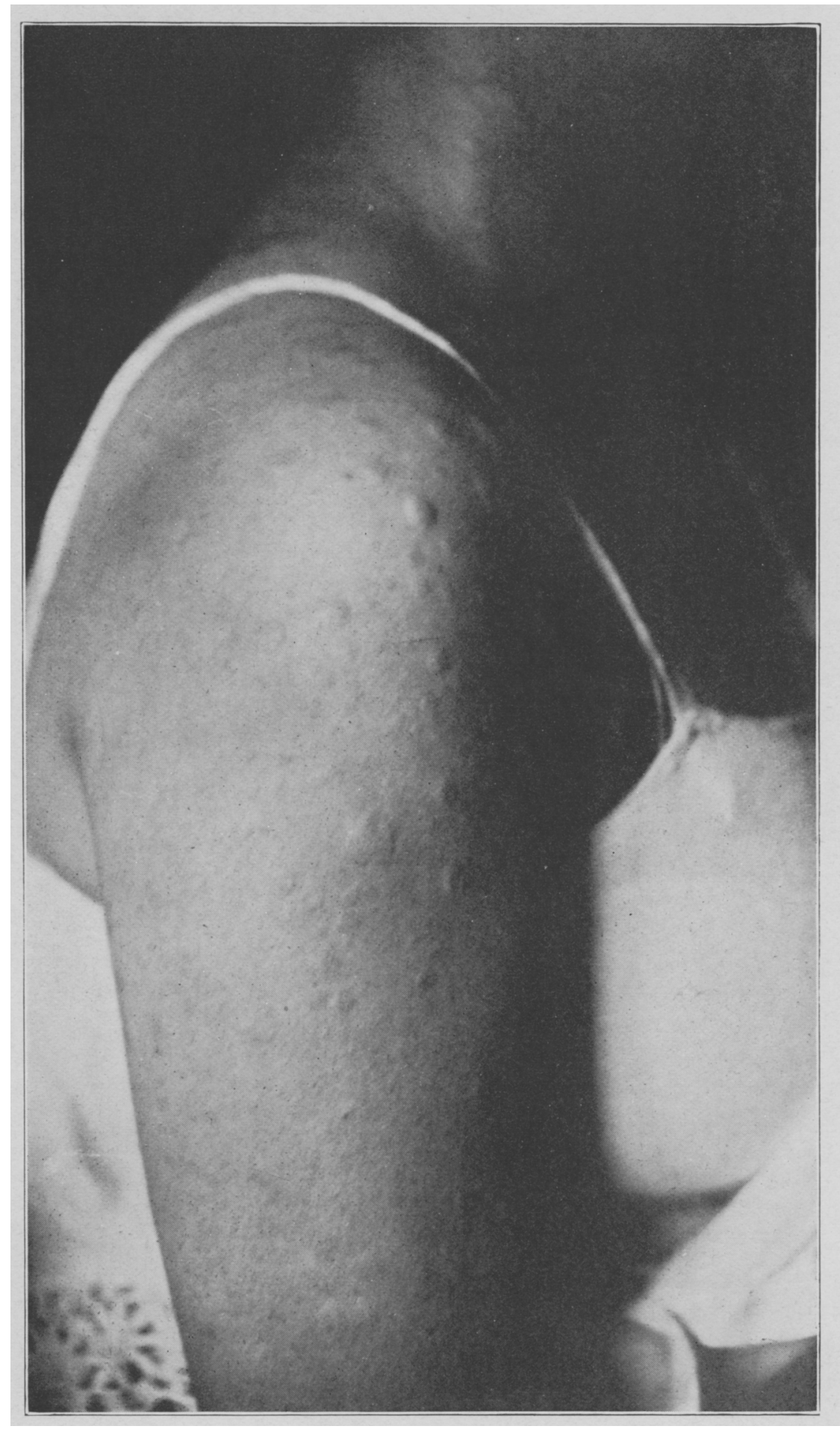

Fig. 1.-Lesions on the right shotlder and arm.

Downloaded From: http://archderm.jamanetwork.com/ by a University of Iowa User on 06/08/2015 
P'ringle "reported a similar case occurring in a man of 21 , showing hard papules, bladder-like tumors and pitted scarring. Pringle maintained that the condition is not a "substansive" disease. A biopsy was not made. (ialloway, in cliscussing Pringle's case, saicl: "There is no doubt atrophy of the skin, which can be called macular atrophy, but the question is whether this preceding tumor-like appearance of the skin is of the nature of a fibroma, or whether it is some form of degeneration of the white connective tissues, associated with actual atrophy of the elastic tissue, allowing this hernial protrusion, including that of the corium and, to some extent, that of the subcutaneous tissue.

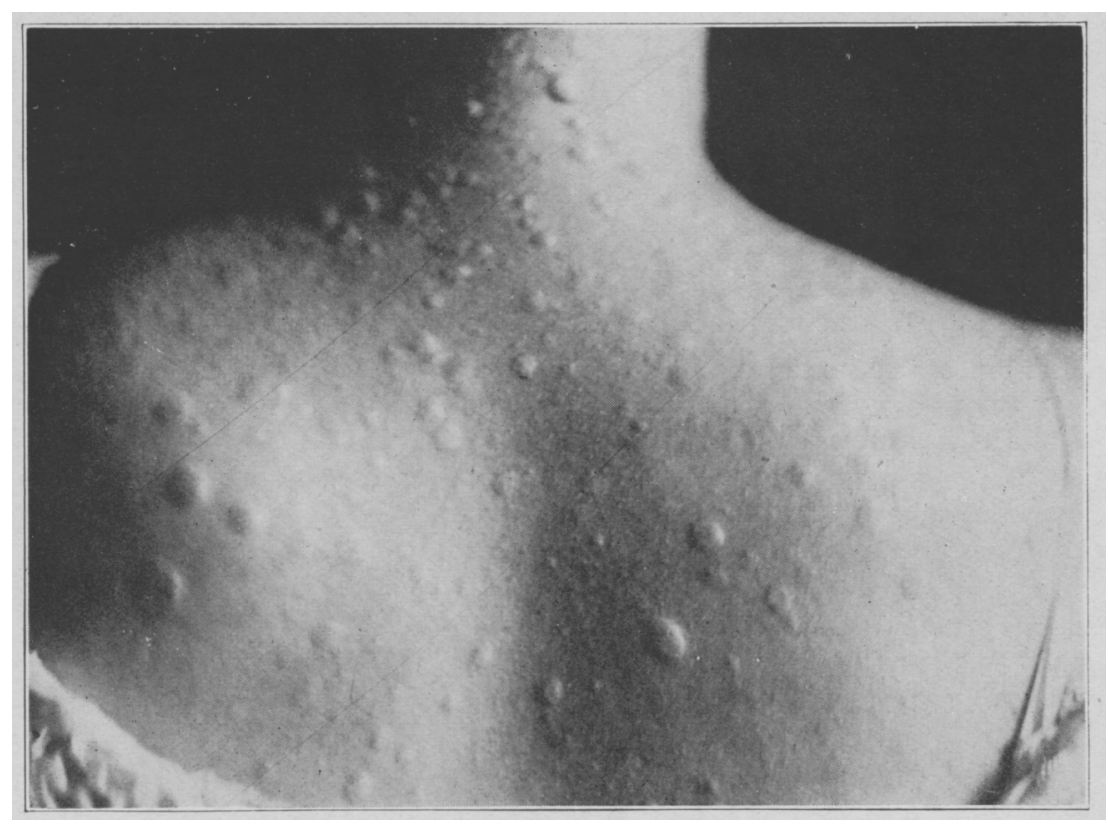

Fig. 2.-Numerous lesions on liack.

That it leads on to a condition of atrophy seems perfectly clear, but we agree we have never seen a case of what we call macular atrophy with this excessive amount of tissue, with increase in bulk, so far as the surface is concerned."

Quinn ${ }^{7}$ recently presented a somewhat similar case before a meeting of the Chicago Dermatological Society. The discussion brought out the opinion that the lesions were not new growths but a macular atrophy.

Of the nine cases previously reported, all are probably examples of the same condition, except the one mentioned by Crocker, which

6. Pringle: Proc. Roy. Soc, Med. 12:21, 1919.

7. Quinn: Arch. Dermat. \& Syph. 5:149 (Jan.) 1922. 
probably belonged to the fibroma group. Only the original case and the one reported by Pusey have been fully reported.

I am able to report a similar case through the courtesy of Dr. H. E. Michelson. The patient was exhibited before the Minnesota Dermatological Society and was shown to Dr. Ormsby when he visited Minneapolis. The consensus of opinion then was that the case resembled very closely the condition described by Schweninger and Buzzi.

\section{REPORT OF CASE}

History-Mrs. O. C. S., aged 28 , a widow, whose family and past history reveal no facts which seem to have any bearing on the dermatologic condition, was a well-nourished and well-devcloped woman. Her apparent age was no older than her actual age.

The condition present had developed ten years previously, beginning with a single small elevation in the right deltoid region. This elevation was of pea size, hard and bluish-white. It caused her no annoyance, but gradually enlarged to the circumference of a 10 -cent piece, and then remained stationary. Insidiously, other similar lesions appeared over the outer surface of the upper arm, the scapular, suprasternal and frontal regions. The patient noticed that the lesions, after being present for some months, retrogressed and became depressed, leaving a wrinkled looking scar.

Examination.-There were numerous small tumor-like projections scattered over the upper anterior and posterior thorax and the arms, and a few on the face and forehead. The lesions varied in size from that of a pea to that of a small cherry. Some were whiter than the normal skin, while others showed a bluish tint, and a few of the lesions had telangiectases over their surfaces. The lesions had the consistency of putty, but there was considerable variation. Some of them were quite soft. The patient stated that the newer lesions were firmer than the older ones. On palpation, many of the lesions could be pushed through a slit-like aperture which admitted the end of the little finger, conveying the impression that the supporting framework had disappeared. The edges of the aperture were smooth and sharply defined. In some locations, the hernia-like lesions had disappeared, leaving the skin over the area thinned and wrinkled in appearance. This scar-like skin was elastic, and when pinched up, seemed to be loosely attached to the underlying tissues. This was evidently the final stage of the disease.

None of the lesions were pedunculated, nor were there any areas of pigmentation or highly pigmented lesions. The surface of all the lesions was smooth, except the wrinkled stage of the older lesions. Sensation was normal, and the location of the lesions seemed in no way to be related to the distribution of the cutaneous nerves. The Wassermann reaction was negative.

Histologic Report.-Three tumors were excised. Two were soft. compressible, old atrophic lesions, while one was an early, firm fibroma-like lesion. The small pieces of tissuc excised were hardened in formaldehyd and alcohol in the usual manner, embedded in paraffin and sectioned serially. Hematoxylineosin and Weigert's resorcin fuchsin stains were used.

Under hematoxylin-cosin, the epithelium showed marked thinning and complete absence of the rete pegs. There was no hyperkeratosis or parakeratosis; 


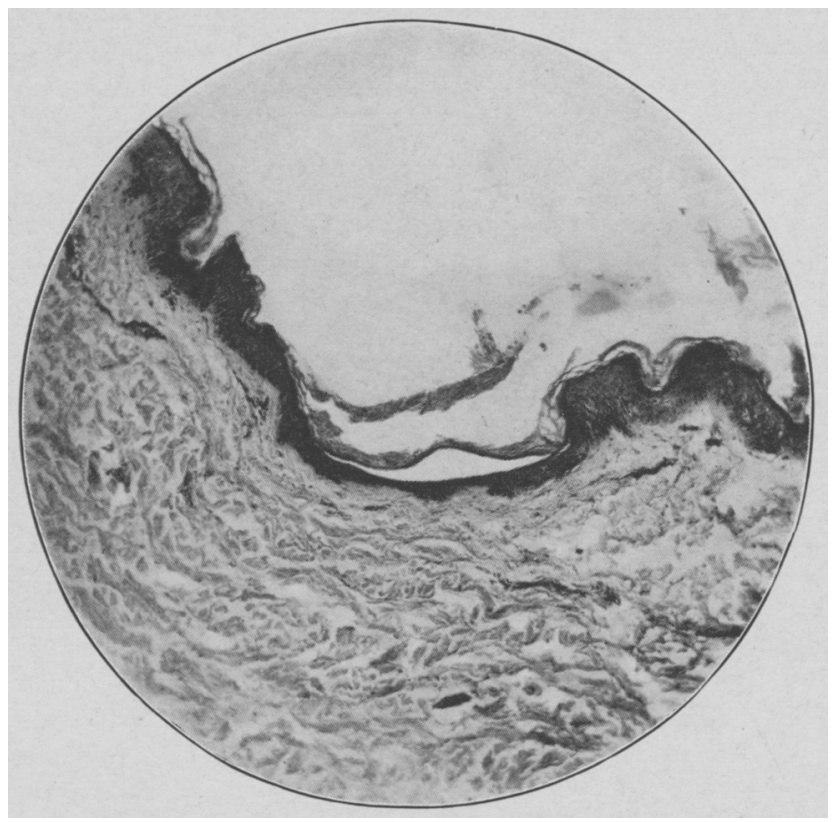

Fig. 3.-Some atrophy of the cpidermis and absence of infiltrate in the corium, with hematoxylin-eosin. (Low power.)

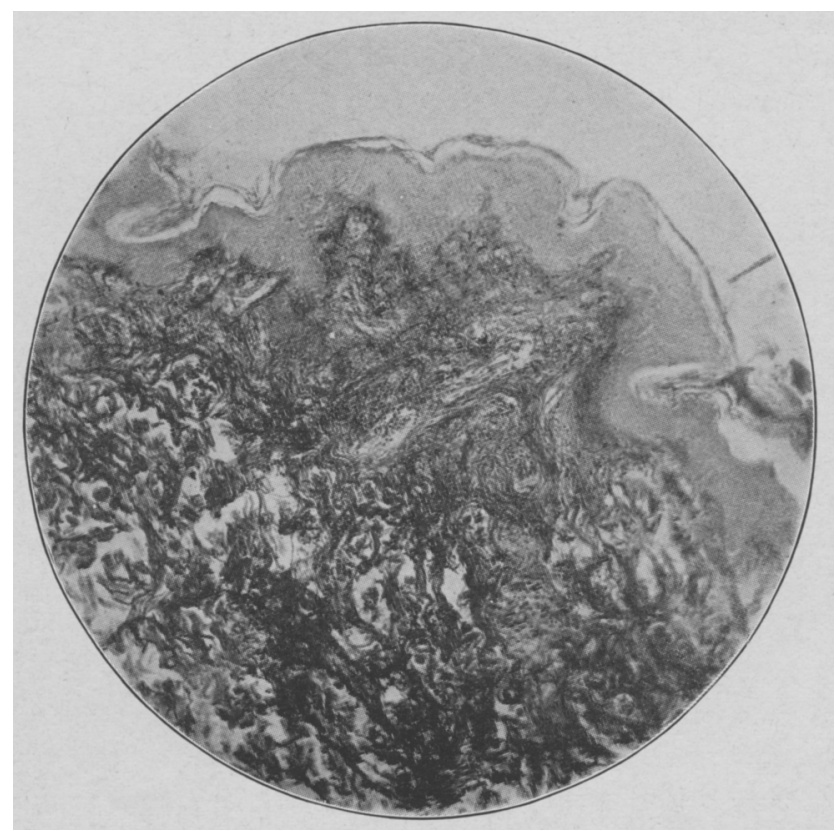

Fig. 4.-New lesion: Elastic filers present at the periphery of lesion, with Weigert's stain. (Intermediate power.) 
nor was there any microscopic evidence of any degenerative processes taking place in the epithelium. There was no infiltration or alsscess formation noted in the epithelium.

Examination of the corium revealed: The papillary lody projections were lacking. There was no edema, nor destruction of the collagen bundles. Here and there, a few clumps of leukocytes, all of the monomuclear type, were noted. An occasional fibroblast was also seen. There was complete alsence of marked infiltration. The sections stained by Weigert's method showed a diminution and atrophy, and in some places complete loss of the elastic filers. most marked in the tuper portion of the center of a clinical lesion. At the periphery of the lesion, the filers appeared heavier and more numerons.

There were no evilences of new growths. The most marked clanges noted were an atrophy of the epidermis and a loss of clastic filers in the central portion of a clinical lesion.

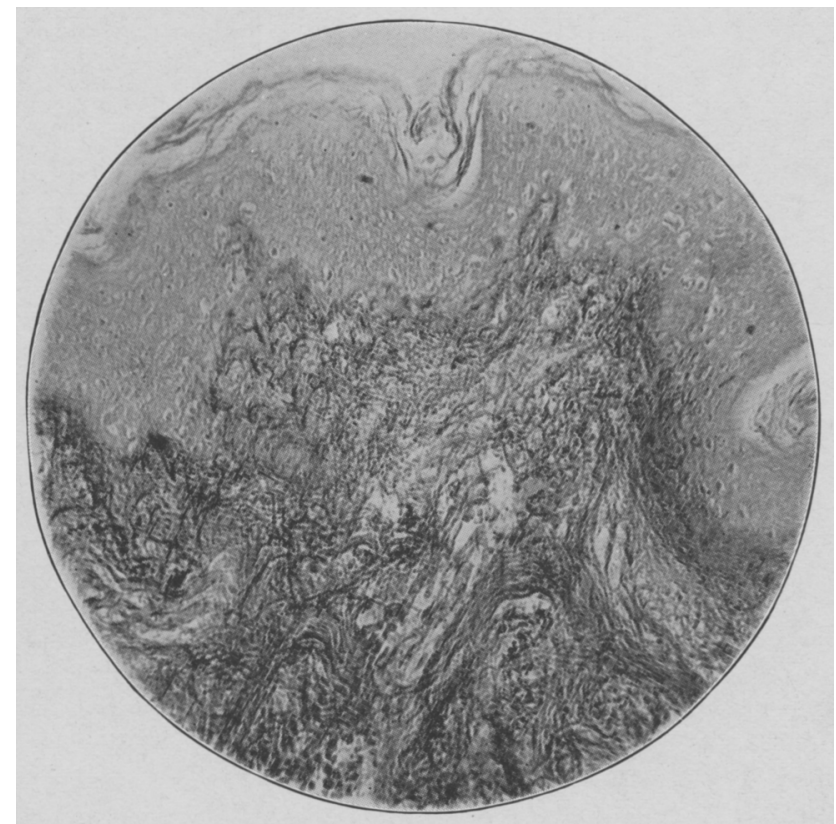

Fig. 5.-Alsence of clastic fihers in upper portion of center of lesion, with Weigert's stain. (Low power.)

These findings correspond to those which have been described as occurring in the tumor-like growths of Schweninger and Buzzi, a condition which this case simulated cinically. This case also corresponded closely to a case reported by l'usey.

In endeavoring to classify the case, one must consider two conditions: (1) fibroma molluscum and (2) macular atrophy. Fibroma molluscum may be looked on as a congenital defect or a nevus syndrome which includes pigmented areas, pedunculated tumors, bone changes, with sometimes kyphosis, and, at times, low mentality. These various conditions are not always present, but typical cases often will show them. 
Comp'ete absence of pedunculation, pigmented lesions or pigmented areas is strong evidence against fibroma molluscum in this case. Furthermore, sections from a recent lesion did not show the typical structures of fibroma.

Macular atrophy is considered to be due to a loss of elastic tissue. Bag-like pouching is not usually seen in macular atrophy, but has been noted when some concurrent edematous process caused pressure in the surrounding tissues. From Pusey's studies and from a study of our sections, we are convinced that there is an actual atrophy of the elastic fibers, with a subsequent increase of the fibers about the lesions, forming a perceptible slit-like hernial opening through which the tumorlike lesions protrude. Schweninger and Buzzi did not believe that the lesions were new growths, but remarked that the tumor-like lesions were composed of normal elements.

From a survey of the literature and a study of our case, we are convinced that the so-called tumor-like growths of Schweninger and Buzzi should be grouped with the macular atrophies.

\section{CONCLUSIONS}

1. This condition should not be regarded as an entity because histologic study reveals that it is a peculiar type of atrophy and not a new growth.

2. We do not believe that this condition is related to fibroma molluscum.

\section{DISCUSSION}

Dr. JAY Frank Schamberg, Philadelphia: This paper has cleared up in my mind the diagnosis in a case of $\mathrm{mv}$ own presented by one of $\mathrm{mv}$ associates before the Philadelphia Dermatological Association with a condition unlike any I had seen. We were all very much puzzled as to the diagnosis. The patient, a niddle-aged woman, had half a dozen or more lesions on the leg that presented a remarkable aspect. At first sight, one would call them large blebs, and only after we had punctured these very distended baggy prominences did we find that they contained no fluid. A small venule ran through soft. wrinkled overlying skin. On pressing this soft growth, the finger went through a small button-hole like opening, through which you could press down the haggy surface. There were other lesions, which had more or less flattened down. presenting a scarred cigaret paper like wrinkling of the skin, but also with this opening at the hase. On account of the resemblance to pemphigus, I suggested that we call it atrophoderma pemphigoides.

I never knew the nature of the disease until Dr. Sweitzer read his paper; but now I am sure from the slit-like opening to which he refers, and the very pronounced atrophy of the skin, that it belongs to this group of cases.

Dr. Walter J. Highman, New York: I was particularly interested in Dr. Sweitzer's presentation because I recall seeing the case Dr. Pusey described at the Cincinnati meeting, and, although I had never heard of the condition before, it struck me that the conclusions of Dr. Sweitzer would be tenable. The condition has all of the attributes of atrophies in general, whether primary 
or secondary. Whether we are dealing with scleroderma or the macular atrophies, or with the cicatricial atrophy or pseudopelade, histologically the same elements are present in the skin, in the disturbance of the elastic tissue. Sometimes, there is a complete disappearance of the collagen, and the crumpling back of the elastic tissue in the vicinity of the lesion: and I feel that this button-hole like sensation imparted to the palpating finger must be really due to the retraction of the elastic tissue. There is a certain vagueness of the tissue when the elastica no longer exists. I think it is only a subvariety of the idiopathic atrophies.

Dr. Charles J. White, Boston: We had at the Massachusetts General Hospital a most remarkable case of acrodermatitis atrophicans in which, preceding the atrophy, were the kind of tumors Dr. Sweitzer has described, giving the same baggy sensation. That was as severe a case as I have ever seen. and with this peculiar. progressive symptom which $I$ have seen in but this one instance.

Dr. Francis E. Senear, Chicago: I had the opportunity of studying Dr. Pusey's case with him. The peculiar feature in our case was the fact that all of the tumors were present on the lower half of the face and neck. On the body, we found many of the slit-like lesions that Dr. Sweitzer has described. The patient, who was unusually intelligent, had never noticed any of the baggy lesions preceding the macular slit-like lesions, although we felt that they perhaps developed from the baggy tumor. In the light of Dr. Sweitzer's observations, I think perhaps the patient's observation was faulty and that they were the end-result rather than the preliminary lesions.

Dr. Samuel E. Sweitzer, Minneapolis (closing): This condition struck us as being a peculiar form of atrophy. In regard to acrodermatitis atrophicans, we frequently find a hard nodule in that disease, but this did not resemble that. There are only the small, tumor-like lesions, and the rest of the skin is normal. The patient presented a few lesions on the face, but they were old lesions and had flattened down and did not photograph well.

The condition apparently began with a small nodule, and we purposely cut out a new nodule as well as an old one to see if we could find any evidence of a tumor growth; but we found only a beginning atrophy in that as well as in the older lesion, so, as nearly as we could find out, the condition began with the small tumors, and eventually the atrophy became sufficiently advanced to make some of the tumors flatten out when the patient was lying down, and on standing, they would puff out.

625 Syndicate Building. 